\title{
Wittgenstein por Rudolf Haller
}

\author{
Roberto Romano
}

\author{
Trouver une langue; - Du reste, toute \\ parole étant idée, le temps d'un langage \\ universel viendra! Il faut être \\ académicien, - plus mort qu' un fossile, \\ - pour parfaire un dictionnaire, de \\ quelque langue que ce soit.
}

(Rimbaud)
Os escritos de Rudolf Haller sobre Wittgenstein, a filosofia austríaca, o Círculo de Viena, representam, entre nós, um avanço. Seu interesse abrange áreas múltiplas da pesquisa científica, lógica, humanística. Um prisma importante é o modo pelo qual o autor interpreta as fontes, abalando procedimentos comuns na história da filosofia. No Brasil, de modo geral, quando se trata de analisar sistemas ou fragmentos teóricos, apresentam-se duas formas de trabalho. A primeira, genética, enquadra os filosofemas num campo a eles "exterior" (social, psicologico, religioso, etc.). Numa variante mais sofisticada, o texto discutido é posto sob a proteção deste ou daquele universo conceitual prestigioso. Deste, naturalmente, os demais precisariam depender. Nega-se, com isto, toda originalidade às frases a serem enfrentadas.

Alêm dessa tendência, temos o modo estruturalista de análise textual. Em nosso país, destacam-se dois nomes por terem definido a forma mentis dos graduados em filosofia na Universidade de São Paulo. Trata-se de M. Gueroult e de V. Goldsmith. Ambos são, categoricamente, contrários à leitura genética. A lógica dos enunciados, eles afirmam, precisa, para intelecção rigorosa, livrar-se de toda empiria, contextos sociopolíticos, ideológicos, religiosos. Assim, coloca-se o texto filosófico num espaço neutro, ignorando o diálogo empreendido pelos pensadores com as formas científicas e culturais de sua época.

Rudolf Haller afasta-se dessas duas matrizes. A sua leitura rigorosa não se prende às "filiações", acarinhadas pelos seguidores do método genético. Notável, neste caso, o modo como ele desembaraça Wittgenstein da camisa-de-força transcendental (kantiana e outras) que lhe pretenderam aplicar. Recolocando o seu analisado na linha do que se produziu na Áustria, discutindo suas determinantes empíricas e lógicas cujo horizonte ê a Inglaterra, Haller ao mesmo tempo indica a vacuidade das filiações (na maioria das vezes, devidas ao uso analógico demasiado rápido de termos técnicos) e define campos epistêmicos mais amplos, com grande potencial heurístico. Escapando às armadilhas do procedimento genético, Haller também elude os riscos do ascético estruturalismo. Lendo seus ensaios, acompanhamos Wittgenstein em diálogo com Goethe, Frazer, Spengler, Weininger, e outros, normalmente postos fora da "nobre" filosofia escolar. De modo
ROBERTO ROMANO é professor de Filosofia Polltica do Departamento de Filosofia do Instituto de Ciências Humanas da Unicamp e autor, entre outros, de Lux in tenebris (Unicamp-Cortez).

Wittgenstein e a filosofia austrlaca: questoes, Rudolf Haller, traduçăo de Norberto Abreu e Silva Neto. Săo Paulo, Edusp, 1990, 152 pp. 
delicado, Haller descreve as oscilações de Wittgenstein durante sua vida produtiva. Recusa o "corte epistemológico" entre o "velho" e o "jovem" filósofo, mostra a grande importância das discussões no Círculo de Viena, ao mesmo tempo em que indica - com senso refinado de matizes - as diferenças no interior deste último. Enfim: desmancha muitas teorias e ilusões dos comentadores.

Desse modo, nem temos a pureza kantiana em Wittgenstein, nem o simples desfalecimento em doutrinas conservadoras. $O$ traço de ambos - Kant e Spengler - não faz de Wittgenstein um êmulo deste ou daquele. Conhecendo as filosofias da subjetividade, o autor do Tractatus mantém a tarefa de clarificar e descrever a linguagem, dela procurando varrer falsas aporias e problemas. Um capítulo rico, neste sentido, dedica-se às relações entre Wittgenstein e o ceticismo. Haller demonstra que seu analisado não foge à razão instaurada por Descartes, e que este não escapa à dúvida. Nem dogma, nem ceticismo de superfície: “...os métodos que Wittgenstein propõe e aplica, apesar de intencionarem a simples descrição, não parecem admitir a possibilidade de certeza absoluta. Porém Wittgenstein tem também um método para estabelecer e, talvez, produzir, certeza inabalável - e isto, eu suponho, signifique certeza absoluta"(1).

Com as cautelas acima, mostra-se um Wittgenstein livre do patrocínio transcendental mas inserido no debate e na cultura de seu tempo. Nas próprias palavras de Haller: "Antes de seguir a sugestão de Wittgenstein de que é possível 'ver' qualquer filósofo dado à luz de muitas interpretações filosóficas diferentes, e antes de buscar semelhanças entre Wittgenstein e outros filósofos, devemos não esquecer de ver o que há para ser visto, e tentar prestar atenção ao que o próprio Wittgenstein recomendou claramente: não dar atenção ao brado de guerra, mas àquilo que lhe serve de base no contexto da ação humana"(2).

Por força das formas hegemônicas no pensamento brasileiro (garantidas no passado por meios pouco filosóficos, como os sabres militares ou crucifixos) o hábito da crítica é pouco valorizado. Embora desconfiando da fala humana, os positivismos comtianos ortodoxos e heterodoxos - e as várias doutrinas contrárias à modernidade (católicas, sobretudo) fugiram à análise da linguagem. Nos setores ditos progressistas, o dogma imperou, soberano. A simples hipótese de examinar ou descrever o funcionamento do discurso foi descartada a priori. Enquanto na Europa a "linha justa" perseguia, ou colocava sob o tacão, lingüistas e filósofos, no Brasil este campo foi "esquecido" pelas esquerdas. Não era "coisa séria". Ainda hoje, em Departamentos de Filosofia respeitáveis por outros títulos, ainda há quem julgue "irrelevantes" as investigações filosóficas sobre a linguagem. Certos docentes valorizam o estudo "verdadeiramente" teórico, o que movimentaria "puros conceitos". Só agora começa a ser reconhecido o trabalho paciente dos que se dedicam ao estudo da lógica, da semântica, retórica, etc.

O livro de Haller será um incômodo para os dogmáticos patrícios. A começar com a divisão mencionada, entre "verdadeiros especulativos" e "empiristas", meros críticos da linguagem. Mesmo quando recolhe esses lugares-comuns do preconceito contra a pesquisa da linguagem, Haller mostra aos dogmáticos de plantão algo que os toca de perto. Por exemplo, a frase rápida, emitida por Weininger, e citada na página 104: "De Bacon a Fritz Mauthner, todos os incultos foram 'críticos da linguagem' ". Locução breve, mas pesado juízo de valor contra a filosofia inglesa e suas ramificações.

Não é o caso de analisar, aqui, os escritos de Weininger. Mas a sentença acima nutrese do irrefletido menosprezo pelo chamado "empirismo" inglês, e também de uma alentada polêmica contra as Luzes, que possui naquele ponto suas bases mais sólidas (Bacon, Locke, Hume e muitos outros). Só para lembrar: "O inglês, diz Weininger, impressionou o alemão como hábil empirista, como político na prática e na teoria, mas com isso esgotou a sua importância para a filosofia. Nunca houve um pensador mais profundo que não houvesse superado o empirismo; e nunca houve um inglês que o houvesse superado independentemente'(3).

Com muita razão Hans Mayer, em seu lancinante livro sobre os "Aussenseiter", localiza Weininger na polêmica romântica e antiiluminista, cujos frutos irracionalistas podem ser colhidos mesmo em Th. Adorno e semelhantes. "Vestígios de sua luta (de Otto Weininger, RR) contra o empirismo em nome da filosofia social e especulativa podem ser encontrados já bem avançado o século: na luta de Adorno contra o positivismo, ou em seus relatórios amargamente irônicos sobre experiências científicas entre os anglosaxões, com sua importuna pergunta pela evidência científica"(4).

Schopenhauer, Hegel, e quejandos, apesar das diferenças que mantiveram entre si, guardaram o mesmo desprezo pelos pensadores que escapam das armadilhas construídas 
pelo Sujeito. Quanto ao primeiro, vale a pena recordar a justa reprovação que recebeu de Goethe, sobre as cores: "Quando Schopenhauer explicou numa de suas conversas de 1813-14 que o mundo sensível era nossa representação e que a luz não existiria se não a víssemos, Goethe fixou-o com seus grandes olhos de Júpiter e disse: 'Não, vós não existiríeis, se a luz não vos enxergasse'"(5). Encontramos ecos dessa atitude em Wittgenstein. Citemos Haller: "É relativamente fácil determinar o que Wittgenstein considera, entre as condiçōes de gramaticalidade, o conteúdo de um livro de gramática: ou seja, concordância entre julgamentos $\mathrm{e}$, sobretudo, concordância na ação. Isso quer dizer que, se não concordamos na nomeação das cores e em nosso uso de palavras para cores, então a questão de se um objeto é ou não de uma certa cor não poderia ser significativamente posta ou, se colocada, não poderia ser significativamente respondida. Se não se pode presumir concordância entre sistemas e escalas de medida, então não existem valores a determinar"(6). Adiante, afirma Haller: “a investigação gramatical não é, no julgamento de Wittgenstein, uma investigação transcendental". E finalmente: "as proposições empíricas podem ser comprovadas ou refu-

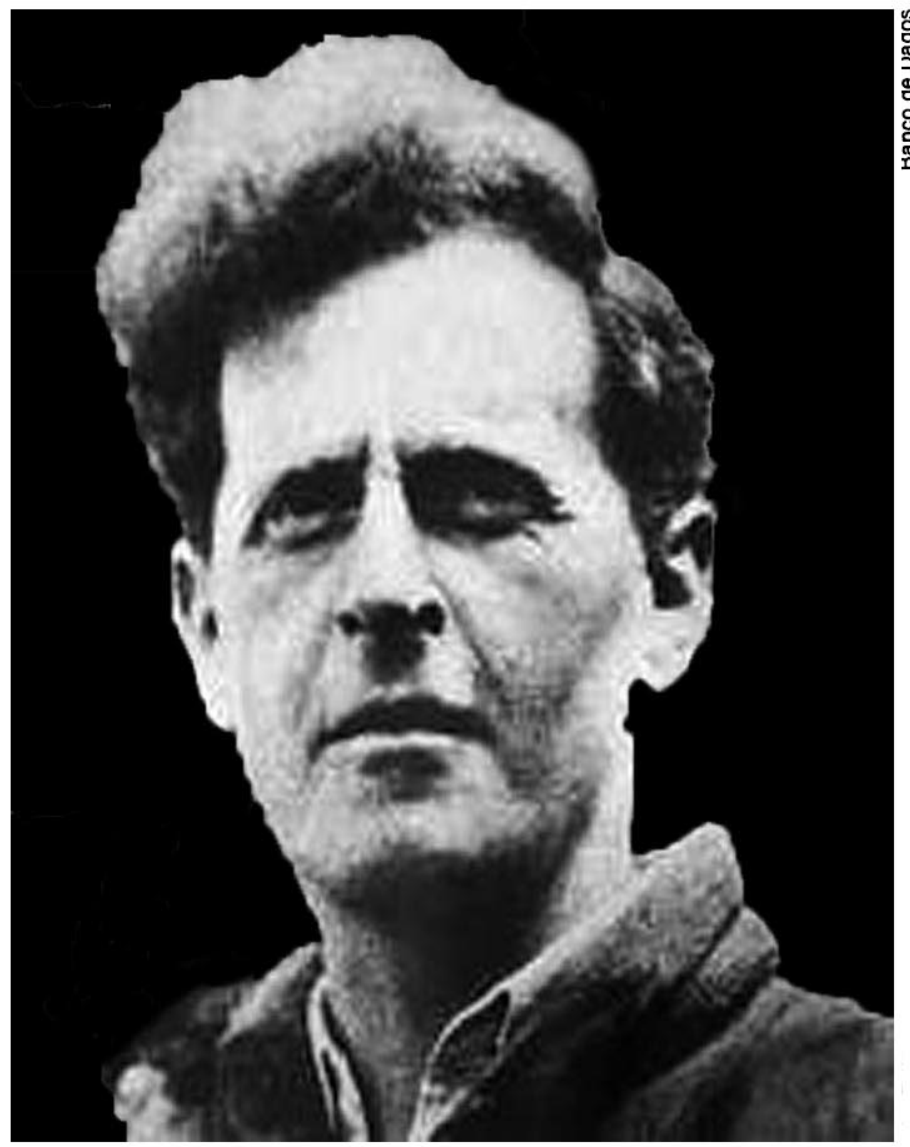
tadas", mas apenas elas. Dizer isto é pecar contra o Espírito, na opinião dos herdeiros mais ou menos ortodoxos de Kant.

A pecha de "incultura", atribuída à filosofia inglesa, tem longa história. Esta é tão renitente, quanto pouco trabalhada, na filosofia dogmática, dialética, ou crítica, a questão da linguagem. Comentando Mauthner, apreciado negativamente por Weininger, junto com Bacon e todo o pensamento inglês, Haller indica, referindo-se a Hamann predecessor de Mauthner e de muita gente ilustre - o seguinte: "Um século depois de Hamann, Gerber reitera que 'Kant não submeteu a linguagem a uma crítica', apesar de ela ser o 'único, o primeiro e o último órgão e critério da razão', como é admiravelmente colocado pelo Magus do Norte'"(7).

Fazendo tabula rasa dos nexos intrincados entre estudo da linguagem e controle conceitual e empírico, os cultores do Sujeito lançam uma densa nuvem de poeira sobre o que justamente Francis Bacon denominou "litterata experientia". Citemos: "Nullo enim modo videntur homines adhuc nosse, quam severa sit res veritatis et naturae inquisitio, quamque parum hominum arbitrio relinquat. Neque tamen nos peregrinum quiddam, aut mysticum, aut Deum Tragicum ad vos adducimus. Nil enim aliud est nostra via, nisi litterata experientia, atque ars sive ratio naturam sincere interpretandi, et via vera a sensu intellectum"(8). Para evitar o misterioso "quiddam", mais tarde chamado "Ding an sich", o sublime "je ne sais quoi" sentimental, ou a Razão absoluta e inefável, Bacon já defende o estudo da linguagem, unido à experiência lucífera. Longe de "incultura", trata-se de uma tentativa para unir as palavras e as coisas, sem reduzir a experiência a uma delas somente.

O exame da língua, importante desde o Novo Organon e a Instauratio Magna até a Encyclopédie, obra coletiva dirigida por Diderot, entusiasta de Bacon, coloca-se justamente contra o uso inflacionário dos "conceitos", os idioletos da Escola. A sátira de Rabelais contra os sofistas (o pedante, no Pantagruel, "pindarise", usa termos abstrusos, pois trata-se de um "ignorans voullans apparoistre") gira ao redor da linguagem(9). As invectivas de Erasmo, as flechas dirigidas pelos humanistas todos contra o jargão escolástico ("What be the fruits of speaking art? What grows by the words? Words", diz Sir Philip Sidney na sua Arcadia) ${ }^{(10)}$, encontraram em Bacon e seus pósteros cultivados parceiros. O que se desejava era evitar que os homens "began to hunt more after

\footnotetext{
5 A. Hübcher, citado por Maurice Elie, in A. Schopenhauer, Textes sur la Vue et sur les Couleurs, Paris, Vrin, 1986, p. 18.

6 Haller, p. 69.

7 Haller, p. 60.

8 F. Bacon, "Redargutio Philosophiarum", in F. Bacon, Récusation des Doctrines Philosophiques et autres Opuscules. Paris, PUF, 1987, p. 115.

$9 \mathrm{Na}$ definiçăo de P. Fabri: "Barbarisme, c'est vice d'escripture ou de incongru langaige (...) ou de langaige parcial en termes barbares, gergon et aultre parler non congneu que en lieu parcial" (citado por G. Defaux, Panparciar (cilado por G. Delaux, Pantagruel et les Sophistes. La Haye, M. Nijhoff, 1973, p. 85. Que diriam os autores do Humanismo de nosso economistas, sociólogos, e ouiıs?

10 Citado por R. Fraser, The Language of Adam. Nova York, Columbia Uni. Press, 1977, p. 4. Seria até tolice lembrar a frase batida de Hamlet. embrar a trase batida de Hamlet, espondendo ao velho pedante e in comodo: "words, words, words.
Tudo, pois, menos "incultura".
}



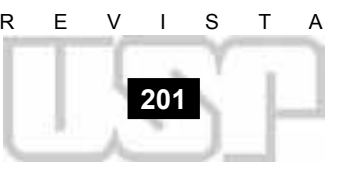


11 Cf. Charles Webster: The Great Instauration, Science, Medicine and Reform, 1626-1660. London, Duckworth, 1975, p. 105

12 G. W. F. Hegel, "Newton", in Geschchte der Philosophie. Werke in Zwan zig Bấnden, 20, III, p. 231.

13 Para uma discussăo de todos estes pontos, cf. F. Gandt, "La Critique de la Mécanique Newtonienne chez $\mathrm{He}$ gel", In Les Orbites des Planètes. $\mathrm{Pa}$ ris, Vrin, 1979, pp. 47 e 138.

14 Cf. P. Szondi, Hegels Lehre von der Dichtung. Uso a traduçáo italiana: La Poetica di Hegel e Schelling. Torino, Rinaudi, 1986, p. 115.

15 Haller, p. 70.

16 Conferir, por exemplo: na poesia. "Der Geist wird so auf seinem eigenen Boden sich gegenständlich und hat das sprachliche Element nur als MITTEL, TEILS der MITTEILUNG, TEILS der unMITTELbaren Äusserlichkeit, aus welcher er als einem clossen Zeichen von Hause aus in sich zuruckgegangen ist. Deshalb bleibt es auch für das eigentlich Poe tische gleichgültig, ob ein Dichtwerk gelesen oder angehort wird; und es kann auch ohne wesentliche Verkümmerung seines Wertes in andere Sprachen ubersetzt aus gebundener und somit in ganz andere Verhältnis se des Tonens gebracht werden". (Werke in zwanzig Bănden, 15, III, pp. 229-30.)

17 Haller, p. 43. words than matter"(11). A escolástica vingou-se, na figura dos "especulativos" alemães.

Antes de parolar, empilhando palavras, é preciso discuti-las, dissecá-las, clarificando-as. Tarefa empreendida com extrema cautela por Bacon, Hobbes, Locke, Hume e toda uma tradição de estudos, não alheia aos progressos da ciência e da técnica, de um lado, e da própria literatura, de outro. Isto, apesar dos resultados brilhantes em teoria e prática, sempre recebeu o insulto de "incultura", especialmente por parte dos pensadores alemães, de Leibnitz ate Hegel. Como se Hume nada tivesse a ver com o despertar do kantiano sono dogmático, e sua análise da língua pouca coisa contribuísse neste plano...

Hegel, o Absoluto que morou em Berlim, costumava dizer da filosofia inglesa, e de Newton em particular, as piores calúnias. Para ele, como o indivíduo que não conheceria estar falando em prosa, "Newton manejava conceitos, pensando tratar diretamente das coisas físicas"(12). A altivez teutônica impediu que Hegel fizesse uma leitura culta, ou simplesmente correta, de Newton. Até hoje, quem deseja divertimento sobre um ridículo quiproquó pode conferir, entre muitos lugares, na Enciclopédia das Ciências Filosoficas hegeliana, o parágrafo 266 , Nota. Ali, o autor da Logica diz textualmente: “Das Beispiel für die Bewegung, die von der vis centrifuga herkommen soll, ist gewöhnlich der Stein, der in einer Schleuder, von der Hand im Kreise bewegt, immer das Streben, sich von ihr zu entfernen, zeige". O texto newtoniano citado por Hegel, não só nesta passagem, mas já em sua tese de doutoramento ("De Orbitis Planetarum") é, nada mais, nada menos, do que a Definição Quinta da Philosophiae Naturalis Principia Mathematica. O texto, escrito pelo inglês tão menosprezado, diz o exato oposto: "Vim conatui illi contrariam... centripetam appelo"(13). Karl Popper faria outra festa com certas passagens...

Cautela maior com a própria linguagem, e com a dos outros, pouparia muito riso aos "especulativos" e proprietários do Absoluto. O jovem e o velho Hegel chamaram, "incultos" pensadores que eles desconheciam, em boa parte por falta de uma correta investigação sobre a linguagem científica. Não apenas na ciência a "teoria" hegeliana da linguagem é empobrecedora. Segundo sua doutrina, "na expressão lingüística, o primeiro momento é a representação interna (Vorstellung), a própria língua sendo apenas um veículo. Hegel define até o ritmo e a eufonia como 'exterioridades' que não constituiriam o elemento verdadeiro e apropriado ao conteúdo; donde segue-se a tese, absurda para nossa concepção atual de poesia, que uma obra poética 'pode ser traduzida em outra língua, sem que seja diminuído o seu valor, ou então, ela pode ser transportada de rima para prosa, e assim, posta em relações tonais inteiramente diversas' "(14). Contra todo este universo de concepções sobre a linguagem, temos as advertências de Mauthner, importantes para Wittgenstein, e recolhidas por Haller: "Julga-se falsamente, quando se presume que a linguagem é o instrumento do pensamento, porque 'Pensamento é Fala', ou 'Pensamento é fala reduzida a seu valor de varejo' "'(15). Prosaico, sem dúvida, mas com maior respeito pela linguagem, do que os jogos de palavra de Hegel, em detrimento do "veículo"(16). Aliás, Haller recorda que "foi Schlick quem mais ou menos defendeu uma posição que bem teria sido defendida por Wittgenstein, ou seja, de que não podemos experienciar relações internas, mas apenas relações externas"(17). Poetas e tradutores de hoje, como Haroldo de Campos, dedicam-se à tarefa de "transcriar" poesia, justo porque pressentiram as incongruências da maneira hegeliana de ver a língua sobretudo a poética - como "veículo" do "puro pensamento". Outro lugar-comum de agora: poesia é feita com palavras, não com "idéias"...

Para Hegel, "Sinn" é uma palavra "maravilhosa": ela exprime ao mesmo tempo a sensibilidade e a inteligência. Como ele não considera essencial que uma poesia seja lida ou ouvida, nesta sua surdez vemos a diferença entre tal doutrina poética e a de nosso tempo: "La poésie - cette hésitation prolongée entre le son et le sens" (Valéry).

Como é possível constatar, o livro de Haller desvela campos insuspeitados na filosofia, ciência, estética, psicologias, etc. Ensaios como os seus estimulam o engenho, projetando o leitor para além das taxinomias gastas, ou das filiações prestigiosas e ilusórias. Os escritos agora publicados em nossa língua ajudarão a clarificar os escritos de Wittgenstein. O melhor será obtido quando os "teóricos" apresentarem maior respeito pela filosofia da linguagem, assumindo o básico em todo trabalho científico: a estranheza diante das "evidências". O primeiro homem que transformou a filosofia num estilo, modo de escrever, já dizia: "O filosofar nasce do espanto". Advertência grave: "Unsinn aber wäre es zu sagen, wir betrachten etwas als sichere Evidenz, weil es gewiss wahr ist" (Über Gewissheit). 